\title{
Quaternized Chitosan as an Efficient Catalyst for Synthesis of $\mathrm{N}$-alkylthio-phthalimides
}

\author{
Zhang $\mathrm{Hu}$ (Corresponding author) \\ College of Science, Guangdong Ocean University \\ Zhanjiang 524088, Guangdong, China \\ E-mail: huzhangqyx@126.com \\ Sidong Li \\ College of Science, Guangdong Ocean University \\ Zhanjiang 524088, Guangdong, China
}

Zhang Hu is grateful for financial support by the Program for Excellent Talents in Guangdong Ocean University (No. 0912118) and by the Natural Science Foundation of Guangdong Ocean University (No. 1012140).

\begin{abstract}
A practical and efficient synthesis of $\mathrm{N}$-alkylthio-phthalimides by the reaction of N-chlorophthalimide with thiols catalyzed by quaternized chitosan was described. The reactions were carried out in relatively mild conditions, and a variety of N-alkylthio-phthalimides were efficiently prepared with moderate to good yields.
\end{abstract}

Keywords: Quaternized chitosan, Catalyst, N-Alkylthio-phthalimides

\section{Introduction}

The development of the N-alkylthio-phthalimides is of considerable interest because of the occurrence of many sulfur-containing compounds in many biologically important compounds (Tudge et al. 2006). Stable $\mathrm{N}$-alkylthio-phthalimides have been used to prepare various N-(thioalkyl)amides (Ito et al. 2002; Ito et al. 2003), $\alpha$-phenylthio-ketones (Wang et al. 2004), disulfides (Wang et al. 2003; Vigushin et al. 2003).

Different methods for preparation of N-alkylthio-phthalimides have been introduced. The synthesis of alkyl and aryl sulfenimides by the reaction of sulfenyl chlorides with imides in the presence of a tertiary amine was reported by Behforouz (Behforouz \& Kerwood, 1969). Klose synthesized some N-alkylthio-phthalimides by the reactions of thiols or disulfides with phthalimides in the presence of bromine in pyridine-acetonitrile solution (Klose et al. 1997).

Chitosan (CS) is a very abundant biopolymer obtained by the alkaline deacetylation of chitin that is present in the exoskeletons of crustaceans, the cuticles of insects and the cell walls of most fungi. Chitosan has been not only extensively used as a support for the preparation of heterogeneous catalysts, but also itself has been used as a catalyst for some reactions. Owing to its biodegradability and non-toxicity, chitosan is considered as an environmentally friendly catalyst (Guibal, 2005). Recently, quaternary ammonium salts covalently bound to chitosan was used as a heterogeneous catalyst for the synthesis of dimethyl carbonate (Zhao et al. 2007; Zhao et al. 2008). We report here that the quaternized chitosan (QCS) can catalyze the reaction of N-chlorophthalimide with thiols under relatively mild conditions yielding N-alkylthio-phthalimides.

\section{Results and discussion}

The QCS catalyst was prepared as shown in Scheme 1. Reaction of CS with glycidyl trimethyl ammonium chloride at $85^{\circ} \mathrm{C}$ for $10 \mathrm{~h}$ in water afforded QCS with the degree of substitution (DS) of $47 \%$. The IR spectra of CS and QCS were shown in Figure 1. Because chitosan with degree of deacetylation of $90 \%$ was used as the starting materials for the quaternization reactions, both spectra of CS and QCS appeared the amide carbonyl signal at $1645 \mathrm{~cm}^{-1}$. In the spectrum of QCS, the $\mathrm{NH}_{2}$-associated peak at $1595 \mathrm{~cm}^{-1}$ was weakened and a new peak at $1485 \mathrm{~cm}^{-1}$ (attributes to the methyl groups in the ammonium) appeared. The characteristic peaks of primary alcohol and secondary alcohol between 1083 and $1150 \mathrm{~cm}^{-1}$ did not change in QCS comparing with CS that showed the introduction of quaternary amino groups at $\mathrm{NH}_{2}$ sites on chitosan chains.

The coupling of N-chlorophthalimide with benzyl mercaptan was studied to identify a suitable catalytic system. 
Catalysts pyridine, CS and QCS were employed to search for the suitable catalyst (as shown in Table 1). It was found that QCS was effective (entry 3). It is noteworthy that QCS demonstrated a comparable activity to that of the homogeneous catalyst pyridine under the same reaction conditions (entries 1 and 3). However, there was only a trace amount of the corresponding products obtained in the presence of CS (entry 2).

The catalytic efficacy of QCS for general N-S bond formation between thiols and N-chlorophthalimide was further evaluated. As summarized in Table 2, the coupling reactions were performed under the condition of 10 mol\% QCS in acetonitrile, the corresponding N-alkylthio-phthalimides 4 were obtained in moderate to good yields. These results demonstrated that QCS could be used as a good promoter for the coupling reactions between thiols and N-chlorophthalimide.

In summary, we have demonstrated that the quaternized chitosan can be used as an efficient and general catalyst for the coupling reactions between N-chlorophthalimide and thiols at relatively mild conditions, and a variety of $\mathrm{N}$-alkylthio-phthalimides were prepared with moderate to good yields.

\section{Experimental}

Melting points were obtained on a B-540 Büchi melting-point apparatus and are uncorrected. FT-IR spectra were recorded on a PerkinElmer Spectrum 100 spectrometer from KBr pellets. ${ }^{1} \mathrm{H}$ NMR was measured with a Bruker $400 \mathrm{MHz}$ spectrometer with tetramethylsilane (TMS) as an internal standard. LC-MS (ESI) spectra were recorded a Finnigan Mat LCQ mass Spectrophotometer $214 \mathrm{~nm}$ using a Betasil $\mathrm{C}_{18}(3 \mu \mathrm{m}, 100 \AA$, $3 \times 50 \mathrm{~mm})$ column. Chitosan with a degree of deacetylation of $90 \%$ was purchased from Shanghai Guoyao Biochemical Co. Ltd (China). Glycidyl trimethyl ammonium chloride was purchased from Dongying Guofeng Chemical Co. Ltd (China). N-chlorophthalimide was prepared according to the reported methods (Mintz \& Walling, 1969; Zimmer \& Audrieth, 1954). The thiols were purchased from Jiande Xingfeng Chemical Co., Ltd (China). Unless otherwise stated, all other chemicals and reagents used in this study were reagent grade.

Preparation of the quaternized chitosan (QCS)

Chitosan $(2.0 \mathrm{~g}, 12.1 \mathrm{mmol})$ was dispersed in isopropyl alcohol $(20 \mathrm{~mL})$. Glycidyl trimethyl ammonium chloride $(7.34 \mathrm{~g}, 48.4 \mathrm{mmol})$ was dissolved in water $(5 \mathrm{~mL})$ and added to the chitosan suspension. The mixture was stirred at $85{ }^{\circ} \mathrm{C}$ for $10 \mathrm{~h}$. The resulting polymer was precipitated by acetone, dialyzed, and finally freeze-dried to

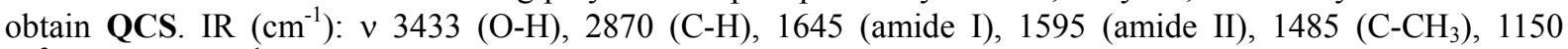
$\left(\mathrm{C}^{2}-\mathrm{OH}\right), 1083\left(\mathrm{C}^{1}-\mathrm{OH}\right)$.

General procedure for the coupling reaction of N-chlorophthalimide with benzyl mercaptan catalyzed by different catalysts

N-chlorophthalimide $(0.5 \mathrm{~g}, 2.75 \mathrm{mmol})$ was dissolved in acetonitrile $(10 \mathrm{~mL})$. The catalyst $(0.25 \mathrm{mmol})$ was added under an argon atmosphere and the solution was stirred and heated to $80^{\circ} \mathrm{C}$. Benzyl mercaptan $(2.5 \mathrm{mmol})$ in acetonitrile $(5 \mathrm{~mL})$ was added dropwise under an argon atmosphere. The mixture was kept at $80^{\circ} \mathrm{C}$ for one hour. Then the reaction mixture was allowed to cool to room temperature. The resulting mixture was filtered and the residue was washed with acetonitrile. The filtrate was evaporated under reduced pressure and the residue was purified by flash column chromatography on silica gel.

General procedure for the coupling reaction of N-chlorophthalimide with thiols catalyzed by QCS

N-chlorophthalimide $(0.5 \mathrm{~g}, 2.75 \mathrm{mmol})$ was dissolved in acetonitrile $(10 \mathrm{~mL})$. The QCS catalyst $(0.055 \mathrm{~g}, 0.25$ mmol) was added under an argon atmosphere and the solution was stirred and heated to $80^{\circ} \mathrm{C}$. Thiol $(2.5 \mathrm{mmol})$ in acetonitrile $(5 \mathrm{~mL})$ was added dropwise under an argon atmosphere. The mixture was kept at $80^{\circ} \mathrm{C}$ for one hour. Then the reaction mixture was allowed to cool to room temperature. The resulting mixture was filtered and the residue was washed with acetonitrile. The filtrate was evaporated under reduced pressure and the residue was purified by flash column chromatography on silica gel. Compounds 4 were characterized by electrospray LC-MS and ${ }^{1} \mathrm{H}$ NMR.

$\mathrm{N}$-(Phenylthio)phthalimide (4a): White solid; ${ }^{1} \mathrm{H}$ NMR (400MHz, DMSO- $\left.d_{6}\right) \delta$ : 7.91-7.93 $(2 \mathrm{H}, \mathrm{m}), 7.81-7.85$ $(2 \mathrm{H}, \mathrm{m}), 7.32-7.41(4 \mathrm{H}, \mathrm{m}), 7.33-7.35(1 \mathrm{H}, \mathrm{m})$. LC-MS (ESI) calcd. for $\mathrm{C}_{14} \mathrm{H}_{9} \mathrm{NO}_{2} \mathrm{~S}[\mathrm{M}]^{+}$255.3, found 255.6.

$\mathrm{N}$-(4-Chlorophenylthio)phthalimide (4b): White solid; ${ }^{1} \mathrm{H}$ NMR $\left(400 \mathrm{MHz}, \mathrm{DMSO}-d_{6}\right)$ 8: 7.91-7.92 (2H, m), 7.82-7.84 (2H, m), 7.43-7.46 (4H, m). LC-MS (ESI) calcd. for $\mathrm{C}_{14} \mathrm{H}_{8} \mathrm{ClNO}_{2} \mathrm{~S}[\mathrm{M}]^{+}$289.7, found 289.5.

$\mathrm{N}$-(p-Tolylthio)phthalimide (4c): White solid; ${ }^{1} \mathrm{H}$ NMR $\left(400 \mathrm{MHz}, \mathrm{DMSO}_{6}\right)$ : $\mathrm{d}_{6}$ 7.90-7.92 (2H, m), 7.81-7.83 $(2 \mathrm{H}, \mathrm{m}), 7.29-7.34(4 \mathrm{H}, \mathrm{m}), 2.26(3 \mathrm{H}, \mathrm{s})$. LC-MS (ESI) calcd. for $\mathrm{C}_{15} \mathrm{H}_{11} \mathrm{NO}_{2} \mathrm{~S}[\mathrm{M}]^{+} 269.3$, found 269.5 .

N-(Benzylthio)phthalimide (4d): White solid; ${ }^{1} \mathrm{H}$ NMR (400MHz, DMSO-d $\left.{ }_{6}\right)$ 8: 7.88-7.91 (2H, m), 7.76-7.82 $(2 \mathrm{H}, \mathrm{m}), 7.37-743(5 \mathrm{H}, \mathrm{m}), 4.11(2 \mathrm{H}, \mathrm{s})$. LC-MS (ESI) calcd. for $\mathrm{C}_{15} \mathrm{H}_{11} \mathrm{NO}_{2} \mathrm{~S}[\mathrm{M}]^{+}$269.3, found 269.5. 
$\mathrm{N}-\left(\right.$ Cyclohexylthio)phthalimide (4e): White solid; ${ }^{1} \mathrm{H}$ NMR (400MHz, DMSO-d $\left.\mathrm{d}_{6}\right)$ 8: 7.86-7.90 (2H, m), 7.76-7.81 $(2 \mathrm{H}, \mathrm{m}), 2.89(1 \mathrm{H}, \mathrm{m}), 1.31-1.93(10 \mathrm{H}, \mathrm{m})$. LC-MS (ESI) calcd. for $\mathrm{C}_{14} \mathrm{H}_{15} \mathrm{NO}_{2} \mathrm{~S}[\mathrm{M}]^{+}$261.3, found 261.6.

$\mathrm{N}-(\mathrm{n}-\mathrm{Hexylthio})$ phthalimide (4f): White solid; ${ }^{1} \mathrm{H}$ NMR (400MHz, DMSO-d $\left.\mathrm{d}_{6}\right) \delta$ : 7.86-7.91 (2H, m), 7.76-7.81 $(2 \mathrm{H}, \mathrm{m}), 2.91-2.93(2 \mathrm{H}, \mathrm{t}, \mathrm{J}=12.0 \mathrm{~Hz}), 1.31-1.61(8 \mathrm{H}, \mathrm{m}), 0.91-0.92(3 \mathrm{H}, \mathrm{t}, \mathrm{J}=10.0 \mathrm{~Hz})$. LC-MS (ESI) calcd. for $\mathrm{C}_{14} \mathrm{H}_{17} \mathrm{NO}_{2} \mathrm{~S}[\mathrm{M}]^{+} 263.4$, found 263.7.

$\mathrm{N}-\left(\mathrm{n}\right.$-Butylthio)phthalimide (4g): White solid; ${ }^{1} \mathrm{H}$ NMR (400MHz, DMSO-d $\left.\mathrm{d}_{6}\right) \delta$ : 7.86-7.91 (2H, m), 7.77-7.81 $(2 \mathrm{H}, \mathrm{m}), 2.90-2.93(2 \mathrm{H}, \mathrm{t}, \mathrm{J}=12.0 \mathrm{~Hz}), 1.54-1.61(2 \mathrm{H}, \mathrm{m}), 1.33-1.40(2 \mathrm{H}, \mathrm{m}), 0.91-0.93(3 \mathrm{H}, \mathrm{t}, \mathrm{J}=8.0 \mathrm{~Hz})$. LC-MS (ESI) calcd. for $\mathrm{C}_{12} \mathrm{H}_{13} \mathrm{NO}_{2} \mathrm{~S}[\mathrm{M}]^{+}$235.3, found 235.5.

$\mathrm{N}$-(n-Propylthio)phthalimide (4h): White solid; ${ }^{1} \mathrm{H}$ NMR (400MHz, DMSO-d 6 ) $8: 7.86-7.91(2 \mathrm{H}, \mathrm{m}), 7.78-7.81$ $(2 \mathrm{H}, \mathrm{m}), 2.91-2.93(2 \mathrm{H}, \mathrm{t}, \mathrm{J}=12.0 \mathrm{~Hz}), 1.56-1.63(2 \mathrm{H}, \mathrm{m}), 0.92-0.94(3 \mathrm{H}, \mathrm{t}, \mathrm{J}=12.0 \mathrm{~Hz})$. LC-MS (ESI) calcd. for $\mathrm{C}_{11} \mathrm{H}_{11} \mathrm{NO}_{2} \mathrm{~S}[\mathrm{M}]^{+} 221.3$, found 221.6.

\section{References}

Behforouz, M. \& Kerwood, J. E. (1969). Alkyl and aryl sulfenimides. J. Org. Chem., 34, 51-55.

Guibal, E. (2005). Heterogeneous catalysis on chitosan-based materials: a review. Prog. Polym. Sci., 30, 71-109.

Ito, M., Okui, H., Nakagawa, H., et al. (2002). Efficient N-sulfenylation of dihydropyrrole derivatives using $\mathrm{N}$-sulfenylphthalimides. Heterocycles, 57, 909-914

Ito, M., Okui, H., Nakagawa, H., et al. (2003). Synthesis and insecticidal activity of novel dihydropyrrole derivatives with N-sulfanyl, sulfinyl, and sulfonyl moieties. Bioorg. Med. Chem., 11, 489-494.

Klose, J., Reese, C. B., Song, Q. (1997). Preparation of 2-(2-cyanoethyl)sulfanyl-1H-isoindole-1,3- (2H)-dione and related sulfur-transfer agents. Tetrahedron, 53, 14411-14416.

Mintz, M. J.\& Walling, C. (1969). $t$-Butyl hypochlorite. Org. Syn., 49, 9-11.

Tudge, M., Tamiya, M., Savarin, C., et al. (2006). Development of a novel, highly efficent halide-catalyzed sulfenylation of indoles. Org. Lett., 8, 565-568.

Vigushin, D. M., Brooke, G., Willows, D., et al. (2003). Pyrazino[1,2- $а$ ]indole-1,4-diones, simple analogues of gliotoxin, as selective inhibitors of geranylgeranyltransferase I. Bioorg. Med. Chem. Lett., 13, 3661-3663.

Wang, W., Li, H., Wang, J., et al. (2004). Direct, organocatalytic $\alpha$-sulfenylation of aldehydes and ketones. Tetrahedron Lett., 45, 8229-8231.

Wang, X., Hu, W., Ramasubramaniam, R., et al. (2003). Formation, characterization, and Sub-50-nm patterning of organosilane monolayers with embedded disulfide bonds: An engineered self-assembled monolayer resist for electron-beam lithography. Langmuir, 19, 9748-9758.

Zimmer, H. \& Audrieth, L. F. (1954). Tertiary butyl hypochlorite as an N-chlorinating agent. J. Am. Chem. Soc., 76, 3856-3857.

Zhao, Y., He, L. N., Zhuang, Y. Y., et al. (2008). Dimethyl carbonate synthesis via transesterification catalyzed by quaternary ammonium salt functionalized chitosan. Chin. Chem. Lett., 19, 286-290.

Zhao, Y., Tian, J. S., Qi, X. H., et al. (2007). Quaternary ammonium salt-functionalized chitosan: An easily recyclable catalyst for efficient synthesis of cyclic carbonates from epoxides and carbon dioxide. J. Mol. Catal. A: Chem., 271, 284-289. 
Table 1. The coupling reaction of N-chlorophthalimide with benzyl mercaptan in the presence of the catalysts ${ }^{\text {a }}$<smiles></smiles>

\begin{tabular}{ccc}
\hline Entry & Catalyst & ${\text { Yield }(\%)^{\mathrm{b}}}^{{ }^{2}}$ \\
\hline 1 & pyridine & 35 \\
2 & CS & 4 \\
3 & QCS & 68 \\
\hline
\end{tabular}

${ }^{a}$ Reaction conditions: benzyl mercaptan (1.0 equiv), N-chlorophthalimide (1.1 equiv), catalyst (10 mol\%), in acetonitrile under $\mathrm{N}_{2}$ atmosphere at $80^{\circ} \mathrm{C}$ for $1 \mathrm{~h}$. ${ }^{\mathrm{b}}$ Isolated yield.

Table 2. N-alkylthio-phthalimids prepared from N-chlorophthalimide and thiols catalyzed by $\mathbf{Q C S}^{\text {a }}$<smiles>[R]SN1C(=O)c2ccccc2C1=O</smiles>

3

4

\begin{tabular}{|c|c|c|c|c|c|}
\hline Entry & Product & $\mathrm{R}$ & Yield $(\%)^{b}$ & MW (found) & $\mathrm{mp}\left({ }^{\circ} \mathrm{C}\right)$ \\
\hline 1 & $4 a$ & & 76 & $255.6\left(\mathrm{M}^{+}\right)$ & $157-159$ \\
\hline 2 & $4 b$ & & 75 & $289.5\left(\mathrm{M}^{+}\right)$ & $177-179$ \\
\hline 3 & $4 c$ & & 71 & $269.5\left(\mathrm{M}^{+}\right)$ & 192-194 \\
\hline 4 & 4d & & 68 & $269.5\left(\mathrm{M}^{+}\right)$ & $165-167$ \\
\hline 5 & $4 e$ & & 66 & $261.6\left(\mathrm{M}^{+}\right)$ & $91-92$ \\
\hline 6 & $4 f$ & & 75 & $263.7\left(\mathrm{M}^{+}\right)$ & $63-65$ \\
\hline 7 & $4 g$ & & 64 & $235.5\left(\mathrm{M}^{+}\right)$ & $68-70$ \\
\hline 8 & $4 \mathrm{~h}$ & & $57^{\mathrm{c}}$ & $221.6\left(\mathrm{M}^{+}\right)$ & $74-76$ \\
\hline
\end{tabular}

${ }^{a}$ Reaction conditions: thiol (1.0 equiv), N-chlorophthalimide (1.1 equiv) and catalyst QCS (10 mol\%), in acetonitrile under $\mathrm{N}_{2}$ atmosphere at $80^{\circ} \mathrm{C}$ for $1 \mathrm{~h}$. ${ }^{\mathrm{b}}$ Isolated yield. ${ }^{\mathrm{c}}$ welded ampoule was used to avoid the less yield due to the low boiling point of n-propanethiol. 


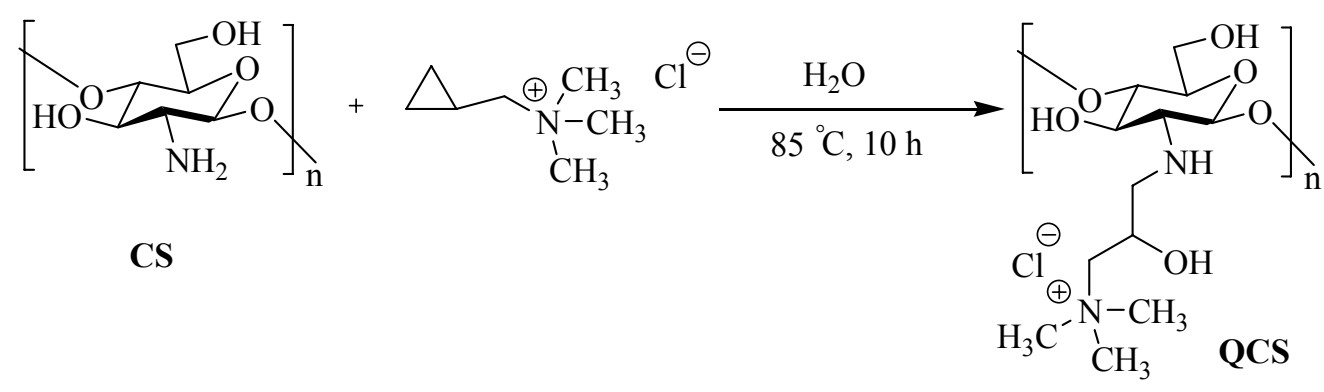

Scheme 1

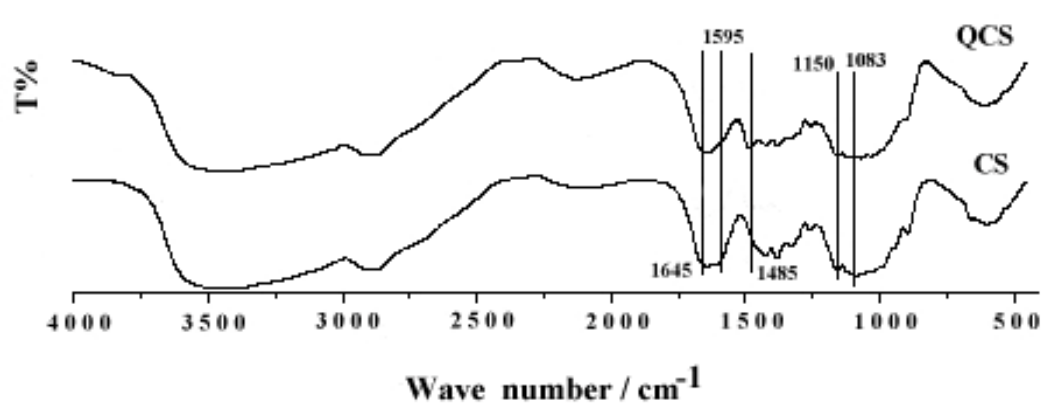

Figure 1. FT-IR spectra for chitosan (CS) and the quaternized chitosan (QCS) 